\title{
Síndrome de Down: trabalho e práticas de inclusão
}

\author{
Dalila Giacomini ${ }^{\mathrm{I}, 1}$, Lisandra Espíndula Moreira ${ }^{\mathrm{II}, 2}$, \\ Mário Francis Petry Londero ${ }^{\mathrm{I}, 3}$ \\ ${ }^{\mathrm{I}}$ Centro Universitário Univates (Lajeado, RS, Brasil)

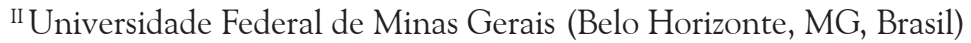

Este artigo analisou enunciados relativos ao trabalho e inclusão para pessoas com Síndrome de Down (SD) que participam de atividades produtivas. Propôs-se uma reflexão genealógica sobre trabalho e sua articulação com inclusão e SD, entendendo que essas marcas funcionam como herança para as possibilidades de inserção nas instâncias do trabalho. A pesquisa foi realizada numa instituição de apoio à pessoa com deficiência, utilizando como metodologias: entrevistas com pessoas que possuem SD e profissionais da instituição, além do acompanhamento das oficinas e confecção de diário de campo. A partir da análise, podemos sintetizar que os enunciados são diversos e apontam para a complexidade do campo. Os enunciados nos apontaram para a importância de três temáticas na forma como as pessoas com SD se relacionam com o trabalho e a inclusão: Construção de vínculos; tempo e ritmo de trabalho; e família e remuneração. Consideramos que o estudo questiona significados atribuídos ao trabalho para funcionários com ou sem Síndrome de Down, possibilitando pensar nas singularidades que constroem formas de inclusão e exclusão no âmbito profissional.

Palavras-chave: Trabalho, Deficiência, Inclusão, Síndrome de Down.

Down Syndrome: work and inclusion practices

This article analyzed statements relating to work and inclusion for people with Down Syndrome who participate in productive activities. A genealogical reflection about work and its relation to Down Syndrome inclusion was proposed, understanding that this traces operate as inheritance to the possibilities of insertion in the instances of work. The research was conducted in an institution for people with disabilities, as methodology interviews with people with Down Syndrome and professionals of the institution were used, further on to the monitoring of workshops and production of field diary. From the analysis we can synthesize that the statements are different and point to the complexity of the field. The statements indicate the importance of three issues in the way how people with Down Syndrome deal with the work and the inclusion: Bond building; time and pace of work; family; and remuneration. We consider that the study questions the meanings attributed to work, for employees with or without Down Syndrome, making it possible to think of the singularities that build inclusion and exclusion forms in the professional scope.

Keywords: Work, Deficiency, Inclusion, Down Syndrome.

\section{Introdução}

No princípio não havia nada, apenas música. No primeiro dia ele fez o sol, dói nos olhos. Então, ele fez a terra. No segundo dia ele fez o mar, ele molha os pés [...] O vento coça. No terceiro dia ele fez os discos... Pessoas nascidas na América falam inglês. Eu não sei onde eu nasci, acho que foi na Mongólia. No quarto dia ele fez a televisão. No quinto dia ele fez a grama. Quando você corta ela, ela chora. Você tem que confortá-la falando com ela. Se você toca uma árvore, você vira uma árvore. Se você fechar os olhos, vira uma formiga. No sexto dia ele fez os homens, eles são de todas as cores. Eu

1 Psicóloga pelo Centro Universitário Univates.

2 Professora adjunta da Faculdade de Filosofia e Ciências Humanas da Universidade Federal de Minais Gerais. Doutora em Psicologia pela Universidade Federal de Santa Catarina.

3 Docente na graduação de Psicologia do Centro Universitário Univates. Doutorando no Programa de Pós-Graduação em Psicologia Social e Institucional da Universidade Federal do Rio Grande do Sul. 
prefiro as mulheres, elas não espetam quando você as beija [...]. No domingo ele descansou, esse foi o sétimo dia (Godeau, 19964).

Iniciamos este artigo inspirados pela descrição da criação do mundo por Georges no filme "O oitavo dia". Menino cativante e com Síndrome de Down, ele desliza de maneira poética sobre a vida ao desviar de possíveis cotidianidades que nos deixam cabisbaixos para o viver. $O$ filme também conta com Harry, que possui conflitos familiares pela rotina sufocante de seu trabalho e que experimenta com Georges afetos que não dava valor, como o simples fato de deitar-se em um gramado e apreciar a paisagem por um minuto que fosse.

Embalados pelo filme e pela inserção dessa pesquisa no cotidiano do trabalho de pessoas com Síndrome de Down, propomos a questão: Quais os desafios colocados para um convívio menos excludente em relação a essa população no que tange à instituição "trabalho"? Eis a problemática que pautou nossa reflexão ao longo da pesquisa realizada em 2013, numa cidade do Rio Grande do Sul. Desde já, gostaríamos de deixar claro que optamos por uma escrita que não se limita à descrição metodológica e analítica do campo pesquisado, no intuito de compormos um mosaico com outros materiais, como o filme que abre esse texto.

Nosso objetivo é compreender os enunciados construídos por pessoas com $\mathrm{SD}^{5}$ a respeito do trabalho e da inclusão em atividades produtivas. Entendemos "enunciado" não como uma unidade, mas como uma função. A análise não busca interpretar uma interioridade a partir desses enunciados, mas compreender as condições que os tornaram possíveis, as posições de quem os enunciam e os campos adjacentes aos quais se associam (Foucault, 2005). Inicialmente, apresentaremos uma forma de compreender os processos históricos acerca da instituição "trabalho" e da deficiência ${ }^{6}$ em si, em especial da Síndrome de Down, inspirados pela ferramenta genealógica de Foucault (1984). Após esse breve percurso, apresentaremos o campo da pesquisa e as análises a partir dos materiais produzidos nas entrevistas e nas interações descritas em um diário de campo que compôs o método de nosso estudo.

\section{Construções sobre trabalho, inclusão e Síndrome de Down}

Inspirados na ferramenta genealógica (Foucault, 1984), propomos uma reflexão histórica sobre as temáticas que envolvem este estudo. Não a história como busca das origens de cada tema, mas como uma problematização de dois aspectos: a proveniência - conjunto de acontecimentos e falhas que os tornaram possíveis e marcam os corpos - e a emergência - ponto de aparecimento e luta de forças. Entendemos que, a partir da problematização genealógica dessas temáticas, é possível analisar os enunciados encontrados na pesquisa, compreendendo-os como herança ou marcas dessa história, que constituem sentidos diversos para trabalho, inclusão e Síndrome de Down.

Em relação ao trabalho, as discursividades que o atravessam e constituem são diversas. A palavra trabalho, do latim tripalium ou trabicula, possui um sentido de tortura. Não à toa, até a chegada do luteranismo, o trabalho era visto como um castigo divino à luz do pensamento cristão. Somente a partir da junção do protestantismo com a classe burguesa nascente na Europa é que

4 Extrato de "O oitavo dia" (Original: "Le huitième jour”), filme de Philippe Godeau e direção de Jaco van Dormael. França, 1996.

$5 \mathrm{SD}=$ Síndrome de Down.

6 Há várias formas de nomear a deficiência e também os sujeitos a ela vinculados: incapacitados, defeituosos, pessoas inúteis, pessoas com necessidades especiais. Optamos por utilizar o termo "pessoa com deficiência", ou apenas PCD, quando estamos falando das deficiências em geral, e SD, quando estamos falando de pessoas com Síndrome de Down. O termo PCD - o mais aceito atualmente - vem substituir "pessoa portadora de deficiência". A palavra "portadora" dá o sentido de que a pessoa porta algo. Logo, parece que a pessoa porta uma deficiência e não que essa deficiência faz parte dela, algo de que ela não pode se desfazer (Fávero, 2007). 
temos uma inversão no valor atribuído ao trabalho, passando a ser visto como algo que dignificava o homem. Nessa virada, podemos verificar a ambiguidade que o trabalho ainda possui. Zanelli, Andrade e Bastos (2004) indicam como algo prazeroso, caso o indivíduo tenha uma boa relação com ele e obtenha sucesso, à luz do que Birman (2003) nos remete a pensar sobre a sociedade do espetáculo, ou, como algo desgastante, quando o trabalho não oferece satisfação e sentimos o peso do fracasso.

Contudo, após a tentativa de sistematização de alguns dos enunciados atribuídos ao trabalho no decorrer da história, o século XX passou a ser o século do emprego e não mais do trabalho. É a preferência pela ascensão a cargos individualistas em uma empresa que está em jogo, e não mais uma formação que identificasse o indivíduo com o seu trabalho e com determinada classe (Deleuze, 1992). A formatação do trabalho enquanto emprego coloca o salário não apenas como retorno pelo serviço, mas como forma de acesso aos bens sociais (Toni, 2003), significante máximo de nossa sociedade capitalista de consumo.

Apesar de identificarmos algumas marcas herdadas dessas construções históricas, os processos de trabalho estão em constante transformação. Quando a sociedade de controle sutilmente vai transformando e dando novos contornos ao que antes poderíamos chamar de sociedade disciplinar, nota-se claramente uma modificação, inclusive na questão dos salários e da dinâmica das relações de trabalho. A fábrica, nascida na sociedade disciplinar, levava suas forças internas a um ponto de equilíbrio em que deveria se produzir muito, mas com o salário do operariado baixo e igual entre todos. Na sociedade de controle, a empresa substitui a fábrica e passa a modular os salários de acordo com a produtividade-competência de cada indivíduo, introduzindo continuamente uma rivalidade que contrapõem os indivíduos entre si (Deleuze, 1992).

Além das transformações históricas, a organização do trabalho pode ser compreendida através da divisão entre o trabalho prescrito e o trabalho real (Liedke, 1997). Essa distinção se refere respectivamente à normatividade e à mobilização subjetiva - a inventividade. Podemos entender que aqui temos a chance de desviar um pouco do tal controle foucaultiano trazido por Deleuze (1992), abrindo brechas inventivas que problematizam o modo de operar o trabalho cotidiano. No trabalho prescrito e cotidianizado, são as normas e leis definidas que estabelecem o processo de trabalho e a forma como ele precisa ser feito do ponto de vista das regras gerais. $\mathrm{O}$ trabalho real seria a forma como o trabalhador, enquanto sujeito, se apropria dessas regras, com adaptações, resistências e ritmos diferentes, que significam o investimento subjetivo para dar conta da tarefa envolvida em cada trabalho. É nessa apropriação que o trabalhador consegue se reconhecer como tal, atribuindo enunciados às suas atividades laborais: "O trabalho é um lugar de problematizações, que convoca os sujeitos a fazerem escolhas no sentido de se dar novas normas, tornando a vida possível de ser vivida no meio do trabalho" (Fonseca, \& Barros, 2010, p. 107).

É na problematização das prescrições da organização do trabalho em relação aos modos efetivos de trabalhar que podemos compreender as marcas do trabalho nos processos de subjetivação. Entendemos que o sujeito se constitui a partir de uma negociação permanente com um conjunto de valores prescritos e regras propostas. Portanto, cabe ao sujeito criar diferentes maneiras de se conduzir perante esses elementos prescritivos, seja sentindo-se comprometido a cumprir determinadas leis, criando formas, ou, mais precisamente, linhas de fuga (Fonseca, \& Barros, 2010). Claro que não devemos cair num discurso ingênuo de achar que linhas de fugas são fáceis de se sustentarem, já que normalmente o que ocorre é uma vampirização pelo capitalempresarial-imperialista sobre aquele que trabalha e cria em suas atividades (Pelbart, 2003). Nesse sentido, aquilo que fazia questão, que resistia e criava novas formas de fazer o trabalho diferente do instituído, do trabalho prescrito, é muitas vezes capturado pelas amarras institucionais, reproduzindo novamente um trabalho burocratizado: o apertar incessante de parafusos, como no filme de Charles Chaplin "Tempos Modernos” de 1936. 
Por meio da perspectiva genealógica, optamos pela análise das práticas coletivas e políticas de resistência dos trabalhadores. Nardi (2006) traz a questão da subjetividade e do trabalho como um campo que se constrói a partir da ruptura de dicotomias como indivíduo-coletivo, objetivosubjetivo e interior-exterior, ampliando a análise para os processos de produção da subjetividade, ou, modos de subjetivação. Pensar a subjetividade nas suas vinculações com o trabalho implica compreender os processos com os quais as experiências do trabalho conformam modos de agir, pensar e sentir, que se conectam com outros elementos como valores, necessidades e projetos de vida de cada sujeito implicado nessa relação com a instituição trabalho.

A partir dessa linha tênue e tensa que delimitamos entre o que chamamos de trabalho prescrito e trabalho real, e entre os atravessamentos institucionais que demarcam o campo empregatício na atualidade, com contrassensos e dissonâncias que operam processos de inclusão e exclusão, e que formatam e alinham os caminhos dos corpos em docilização constante, passamos a analisar a abertura do trabalho para a inserção das PCDs e das pessoas com SD.

A ampliação das exigências aos trabalhadores atrelada ao incentivo à competitividade acarretaram diversas dificuldades para as pessoas que buscam um meio de se inserirem nesse campo, cada vez mais seletivo e restrito. Nesse cenário, a deficiência pode ser confundida com incapacidade por se ter o entendimento de que essas pessoas não desempenham adequadamente seu papel de trabalhador, ou seja, não contribuem produtivamente para as empresas em seu furor produtivo.

A efetivação da inclusão encontra dificuldade pela herança de competitividade, pelas exigências direcionadas aos trabalhadores e pelas marcas atribuídas às pessoas com deficiência. Temos historicamente constituído um modelo de indivíduo que se enquadre nos padrões estéticos, mentais e produtivos que a sociedade espera, sendo assim, tudo que foge desses padrões considerados "normais" é visto como diferente e, mais que isso, inferior e incapacitado.

O campo do trabalho pode ser tomado como uma das ferramentas fundamentais para a construção das interações humanas, ocupando um dos papéis centrais na vida de quem o realiza. É importante pensar nos efeitos do cenário atual e na necessidade de políticas de inclusão para garantir ou facilitar a participação de determinadas parcelas de trabalhadores ao mercado formal, abrindo espaço para uma série de indivíduos que se distanciam do cidadão "ideal": idosos, pessoas com deficiência e desempregados. Segundo Sassaki, tais práticas repousam "em princípios até então considerados incomuns, como: a aceitação das diferenças individuais, a valorização de cada pessoa, a convivência dentro da diversidade humana e a aprendizagem através da cooperação" (Sassaki, 1997, p. 41).

A partir do final da década de 1970 e início de 1980, algumas ações de defesa dos direitos das pessoas com deficiência ficaram mais claras, principalmente com a preparação para o Ano Internacional das Pessoas Deficientes (AIPD) ${ }^{7}$, fortalecendo-se na década de 1990, quando "ocorreram alguns movimentos para que as diferenças culturais, sociais, individuais, econômicas, políticas, étnicas e religiosas fossem respeitadas e acolhidas" (Oliveira, \& Leite, 2002, p. 92). Porém, a efetivação dessas mudanças ainda é um desafio.

A inclusão de PCDs no mercado de trabalho vem ganhando forma através de leis que garantem o acesso privilegiado ao trabalho, estabelecendo a reserva de vagas no quadro funcional das empresas. Das práticas de inclusão que articulam trabalho e deficiência, a mais visível no Brasil tomou forma na década de 1990, através da Lei no 8.213, de 24 de julho de 1991, também conhecida como Lei de Cotas (Brasil, 1991), que garante vagas em empresas para pessoas com deficiência

7 Em 1976, a Assembleia Geral da ONU declarou o ano de 1981 como o Ano Internacional das Pessoas Deficientes. O objetivo do Ano Internacional foi o de promover todos os esforços, nacionais e internacionais, para proporcionar aos deficientes uma assistência adequada, treinamento, orientação cuidadosa, oportunidades para trabalho compatíveis e sua plena integração na sociedade (BRASIL, 1981). 
(habilitadas) ou acidentados de trabalho beneficiário da Previdência Social (reabilitados), variando de $2 \%$ a $5 \%$ do quadro de funcionários, dependendo do total de empregados que a empresa possuir. A legislação vale para empresas com 100 ou mais funcionários, e cabe ao Ministério do Trabalho, através das Delegacias Regionais do Trabalho, fiscalizar o cumprimento dessas cotas nas empresas. Tal processo abre um espaço no qual os trabalhadores com deficiências possam desenvolver suas potencialidades. Esse cenário significa a oportunidade de ser inserido no mercado de trabalho e, a partir dele, desempenhar um papel ativo na sociedade, demonstrando suas potencialidades enquanto profissional e cidadão (Freitas, \& Marques, 2009).

Mesmo com a inserção através das cotas, as PCDs possuem os mesmos direitos trabalhistas e previdenciários. Além disso, o Decreto no 3.298 de 20 de dezembro de 1999 (Brasil, 1999) garante algumas condições para que as PCDs tenham direito à colocação seletiva quando dependem da "adoção de procedimentos e apoios especiais para sua concretização, por exemplo, jornada variável, horário flexível, proporcionalidade de salário, ambiente de trabalho adequado às suas especificidades, apoio de ledores, entre outros destinados a compensar dificuldades de mobilidade e de comunicação" (Fávero, 2007, p. 102).

Segundo um estudo realizado em Bauru, apesar da determinação legal, a maioria das empresas não cumpria a Lei de Cotas, ou seja, não havia promoções de ascensão profissional para as PCDs contratadas. A resistência à contratação se mostra na diferenciação dentro da própria categoria de deficiência, percebida quando mesmo com a legislação se propondo inclusiva, são produzidas especificidades e desigualdades por algumas empresas que selecionam "pelas deficiências menos comprometedoras ou aquelas que supostamente são favoráveis para as linhas de produção" (Violante, \& Leite, 2011, p. 79).

Através da articulação entre trabalho e deficiência, compreendemos ser importante levantar algumas singularidades em relação à Síndrome de Down. Fazendo jus à perspectiva genealógica, cabe situar que a SD passou por diversas concepções ao longo da história, inclusive antes de ser caracterizada e diferenciada. Em 1886, Langdon Down classificou etnicamente os tipos de deficiência mental existentes, e foi durante esse trabalho que categorizou o mongolismo como determinado grupo étnico de deficiência devido a sua semelhança com o povo mongol. Essa categoria depois foi nomeada como Síndrome de Down em homenagem a ele. Em meados do século XX, com o advento das pesquisas genéticas, reformulou-se a concepção dessa deficiência, que deixou de ser vista como uma degradação progressiva da raça e passou a ser tomada como uma condição genética na qual o par cromossômico 21 conta com um gene a mais, podendo ser denominada de "trissomia do 21" (Wuo, 2007).

$\mathrm{Na}$ época da categorização realizada por Down acreditava-se que os fenômenos patológicos estariam ligados a regressões das raças mais primitivas da história, fortalecendo a tese de degenerescência (Wuo, 2007). Essa alteração teórica implicou em uma transformação na concepção social da SD, que deixou de ser uma ameaça de degeneração à raça humana para se tornar uma vítima de sua própria genética (Wuo, 2007). A Síndrome de Down surge como mais uma tentativa de categorizar uma expressão humana que foge do padrão normalizado, pois era através da deformidade do corpo que se comprovava a deficiência.

É através da transformação na concepção da deficiência que se produzem também as alternativas e estratégias necessárias para a circulação das PCDs no âmbito social. De acordo com a Política Nacional para a Integração da Pessoa Portadora de Deficiência, "deficiência é toda perda ou anormalidade de uma estrutura ou função psicológica, fisiológica ou anatômica que gere incapacidade para o desempenho de atividades dentro do padrão considerado normal para o ser humano" (Brasil, 1993a). Entretanto, o limite entre o que é normal e o que é patológico torna-se impreciso se, como nos propõe Canguilhem (1990), tomarmos o indivíduo como ponto de referência, pois as condições orgânicas que são adequadas para um podem não ser para outro. 
O normal não tem um determinante para todos os indivíduos da mesma espécie, mas sim a flexibilidade de uma norma que se transforma em sua relação às condições individuais. Portanto, não é uma média estatística que vai nos dizer se determinado indivíduo diante de nós é normal ou não, mas "é pela anomalia que o ser humano se destaca do todo formado pelos homens e pela vida" (Canguilhem, 1990, p. 89).

Apesar da transformação das explicações científicas para a Síndrome de Down, permanecem as marcas de outras concepções formuladas em distintos períodos históricos, como, por exemplo, a ideia de que as pessoas com essa síndrome são frágeis, incapazes e precisam de alguém que as monitore o tempo todo. Cunningham ressalta que nem todas as pessoas com a síndrome têm as mesmas características, ou o mesmo grau de determinada característica. Existem diferenças em termos de capacidades intelectuais, altura, peso, sociabilidade, personalidade, entre outras que são tão significativas quanto as diferenças entre todos nós: "a Síndrome de Down não é um rótulo fixo, mas uma declaração de probabilidade sobre um ser humano. Não é apenas uma condição, mas um fenômeno completo" (Cunningham, 2008, p. 11). Esse fenômeno envolve não somente aspectos biológicos, mas também sociais, econômicos, políticos e históricos. Um exemplo disso está no fato de pessoas com deficiência nascidas em famílias com maior poder aquisitivo terem acesso a uma série de serviços que as menos favorecidas não têm. Serviços importantes para o desenvolvimento pessoal, aprendizado de habilidades e preparação para o mercado de trabalho.

Durante muito tempo, a forma de lidar com pessoas com Síndrome de Down era mantendoas no âmbito doméstico, delegadas ao convívio e cuidado da família. Práticas excludentes que se mantinham com a justificativa de que seria um benefício para as pessoas com Síndrome de Down, pois as protegeriam (Cunningham, 2008).

A inclusão de pessoas com deficiência intelectual no mercado de trabalho questiona as marcas históricas que posicionam esses sujeitos como incapazes de desenvolver uma atividade laboral. Com isso, pode-se pensar que a inclusão não acontece deslocada desses atravessamentos que ficam evidentes nos ambientes de trabalho. Há que se fazer esse resgate histórico, problematizando-o, para não continuarmos a reproduzir um modelo naturalizado pelo qual todos têm que estar na "ponta dos cascos" para responder à demanda capitalista de produção e consumo em uma velocidade cada vez mais acelerada.

\section{Adentrando o campo: aportes metodológicos}

A pesquisa foi realizada a partir da inserção numa instituição de apoio à PCD, que possibilitou como material de análise o acompanhamento de oficinas e a realização de entrevistas com pessoas com SD e com as profissionais responsáveis por essas oficinas.

Quanto às entrevistas, foram realizadas com seis pessoas com SD vinculadas às oficinas terapêuticas e inclusivas, e uma entrevista com uma pessoa com SD inserida no mercado de trabalho formal ainda com vínculo semanal na instituição. Esses participantes tinham idades entre 22 e 35 anos, e mais de seis anos de vínculo com a instituição. As entrevistas eram acompanhadas pela professora da oficina onde cada um estava inserido para que ela intermediasse quando necessário, auxiliando na compreensão da fala dos entrevistados que tivessem maior dificuldade de se expressar.

Foram também realizadas três entrevistas com profissionais responsáveis pelas oficinas ${ }^{8}$, com idades entre 48 e 52 anos, todas vinculadas à instituição há mais de 20 anos, com ensino superior completo e especialização em educação especial.

8 A pesquisa foi aprovada pelo Comitê de Ética em Pesquisa. Todos os participantes receberam informações sobre os objetivos e assinaram o Termo de Consentimento Livre e Esclarecido. No caso das pessoas com Síndrome de Down que participaram da 
Seguindo a metodologia de entrevista semiestruturada (Manzini, 1990), elaboramos um roteiro com algumas perguntas. Contudo, no decorrer dos encontros percebemos que necessitávamos de uma abertura de escuta ainda mais ampla, dando outros contornos para a entrevista. Apostamos em um percurso de entrevista que permitia uma variação dependendo da singularidade do entrevistado. Já o acompanhamento das oficinas tinha como proposta metodológica a observação e a interação com os participantes, sendo um espaço rico para analisar a forma como organizavam seus trabalhos. O acompanhamento das oficinas foi registrado por meio de diários de campo.

No decorrer da pesquisa não buscamos uma "verdade" sobre a pessoa com SD ou a verdadeira representação do trabalho para elas. Desejamos, pelo contrário, experienciar narrativas que problematizassem essas situações e, por isso, deslocassem o que se encontra de alguma forma naturalizado nos discursos. É preciso mais que constatar certos modos de entendimento sobre o social, é necessário produzir análises que tensionem e desnaturalizem as discursividades que estão aí para moldar o que não tem lugar no mundo. Tal experiência de entrada no campo para confeccionar possíveis narrativas foi perpassada e inspirada por um filme chamado "Colegas". A película traz acontecimentos simples da vida através dos olhos de três jovens com SD que decidem abandonar o instituto onde moravam para ir em busca de seus sonhos. Inspirados no filme "Thelma \& Louise", os jovens fogem no carro do jardineiro sem um destino certo, mas com a certeza de que todos irão realizar seus sonhos. Os três passam a assaltar bares e lanchonetes para se alimentar. Numa cena, policiais decidem interrogar individualmente os colegas de instituição a fim de descobrirem pistas do paradeiro dos jovens. De uma forma um tanto rude, os investigadores os questionavam através de perguntas bem objetivas. A situação parecia ser importante e divertida, pois estavam auxiliando em uma investigação. No entanto, as respostas dadas não condiziam com as perguntas feitas:

Investigador: Desembucha, vai, desembucha!

Entrevistados: Três meninos, foram lá na escola, pegou o carro e ele foi muito bem longe! Eles pegaram o carro e foram direto lá em Las Vegas... Eles roubaram um projeto de pedras preciosas, anéis... Eu vi uma coisa, tinha um fio solto, explodiu! Quero mandar um beijo pro país inteiro, que eu amo muito! É legal pra dançar o Michael Jackson né, mas quando ele morreu eu fiquei no lugar dele. Rebolation sabe, dançando, tirando a roupa, sabe?

O investigador insiste em ter uma resposta concreta, quer saber o paradeiro dos três: Vocês sabem onde eles foram, ou não?

As respostas seguem essa linha: Espanha, Japão... Na selva, Itália, Holanda, México... Ele foi no Shopping, no cinema... Ele pega o sorvete e vai... (Galvão, 2013).

Da mesma forma que no filme, na pesquisa, quase caímos no erro de encarnar os policiais, investigando os sentidos do trabalho. Contudo, fomos surpreendidos pelo encontro, pois apesar do roteiro de entrevista seguir uma sequência que nos parecia inicialmente lógica, a lógica dos encontros subverteu o roteiro. $\mathrm{O}$ que eles tinham a falar, expressar através de gestos, sorrisos e afetos era muito mais rico do que o simples fato de responderem o que estava no script do expert pesquisador.

entrevista, os que o sabiam, assinaram o documento, e para todos foi também colhida a assinatura de seus responsáveis. Para garantir proteção e confidencialidade da identidade dos sujeitos entrevistados, garantindo seu anonimato, utilizamos nomes fictícios.

9 Filme brasileiro dirigido por Marcelo Galvão em 2013. 
Além dos momentos de entrevista, foram acompanhadas as oficinas realizadas na instituição e que são voltadas ao mercado de trabalho. Cada um desses espaços tem características distintas. Existe a Pré-Oficina que objetivava verificar as habilidades e perceber o que cada um gosta de fazer para, posteriormente, serem conduzidos para as outras oficinas que visam um trabalho mais direcionado; a Oficina Terapêutica Produtiva I, na qual o que é produzido é vendido, tendo a característica de serem trabalhos artesanais; a Oficina Terapêutica Produtiva II, na qual as principais atividades desenvolvidas eram a confecção de sacolas de Páscoa e Natal, nas quais os alunos pintam, recortam, colam e a professora fica responsável pelo acabamento. Além do trabalho terceirizado no empacotamento de papel higiênico para uma empresa da região, segundo Marcela (MA.):

Quando a empresa traz os papéis e pede certa urgência para o empacotamento, a gente junta a minha turma e a da Ana (Pré-oficina) para render mais; caso não precisem com tanta urgência, a gente faz com mais calma, intercalando com as demais atividades das oficinas (MA.).

E por fim, segundo Diana (D.), o Acompanhamento com as PCDs, que são reuniões com aqueles que estão inseridos no mercado de trabalho. Entre eles há um com Síndrome de Down: "Procuramos proporcionar um momento diferenciado, no qual eles possam trazer suas dúvidas, angústias, alegrias e que possam também manter um contato com os demais". (D.)

\section{Resultados e análises}

A análise dos materiais levantados inspirou-se na ferramenta genealógica de Foucault, no que ela se contrapõe aos postulados de busca de origem e continuidade. $\mathrm{O}$ olhar genealógico não pretende "recuar no tempo para restabelecer uma grande continuidade para além da dispersão do esquecimento; sua tarefa não é a de mostrar que o passado está lá, bem vivo no presente" (Foucault, 1984, p. 21), mas propor que se faça outra história, na qual haja uma destruição das evidências e se "reintroduza o descontínuo em nosso próprio ser, que faça ressurgir o acontecimento no que ele tem de único e agudo" (Foucault, 1984, p. 28). Para tanto, após profunda leitura e debate dos materiais articulados com o percurso teórico construído, elencamos três eixos principais: 1) Construção de vínculos, 2) Tempo e ritmo de trabalho, 3) Família e remuneração.

\section{Construção de vínculos}

Em uma tarde chuvosa e fria, me dirijo à sala da professora Ana, a fim de fazermos algumas combinações quanto aos dias que eu poderia fazer as observações e as entrevistas na turma dela. A sala está silenciosa, e no canto de uma mesa estava João, colando pequenos pedaços de E.V.A. em uma cartolina. A professora logo me apresenta a ele, que todo sorridente me retribui o "oi". Explico a ele o porquê de estar ali e informo que na próxima semana será entrevistado por mim. Ele dá um sorriso e continua o seu trabalho. Perguntei à professora se naquela tarde somente ele estaria na oficina: "Ah... Tem outros, mas hoje o tempo não está colaborando. Dias de chuva assim são poucos que comparecem". Alguns minutos depois chega Clara. Percebo que causo um estranhamento. Ela passa por mim sem me olhar e cumprimenta a professora com um beijo e um abraço afetuoso. A "profe" Ana logo explica quem sou e o motivo de estar ali. Ela resiste por um instante, mas quando fica sabendo que também será entrevistada na próxima semana fala baixinho: "Eu posso dar um beijo e um abraço nela também?". A partir de então viramos amigas, e acabo sabendo que Clara já foi aluna de todas as 
"profes" e que "retornou" à pré-oficina, não por ser incapaz de produzir nas outras, mas por ter um afeto maior pela professora Ana. O que importa para ela ali? (Diário de campo, 14 agosto 2013).

$\mathrm{Na}$ instituição em que a pesquisa foi realizada, as oficinas são pensadas de forma gradual: tudo se inicia na pré-oficina, testando as habilidades dos participantes para que, na medida em que fossem desenvolvendo algumas capacidades, pudessem avançar para as oficinas terapêuticas produtivas. Entretanto, se Clara, opta por ficar com a "profe" Ana, estaria ela regredindo nesse processo? Ao que tudo indica, não. A lógica de olhar para a singularidade e desejo de cada um abre espaço para que os jovens possam "escolher" em qual oficina querem interagir, conforme a afinidade com a professora, os colegas e as atividades, como expresso pela professora Ana (AN.):

Eles gostam muito de vir pra escola, eles têm prazer em fazer as atividades. Inclusive, uma das alunas com Síndrome de Down que está na minha oficina teria a capacidade de estar nas outras oficinas, até já participou, mas preferiu ficar aqui (AN.).

A organização do trabalho nas oficinas poderia representar um progresso do trabalhador, no qual mudar de tarefa e oficina significariam uma evolução da capacidade produtiva. No entanto, essas "regras" não restringem Clara (CR.) que frequenta essa instituição desde pequena e considera as atividades que faz ali um trabalho. Quando perguntada se gostaria de trabalhar em alguma empresa da região a mesma responde: "Não! Eu gosto daqui!" (CR.).

Poderíamos perguntar o porquê dessa escolha de Clara pela instituição onde está para analisar a necessidade de lugares que acolham as singularidades. Não somente para ser politicamente correto, mas para entender que, justamente são essas as singularidades que podem vir a problematizar e mesmo transformar as relações de trabalho já duras e instituídas. Há uma potência nas relações de trabalho quando elas absorvem as singularidades de cada sujeito implicado, pois abrem brechas para o trabalho real que apontamos anteriormente (Liedke, 1997). Diferente de um trabalho serializado e regimentado, que acaba por produzir relações frias e pouco acolhedoras, a instituição visa sair dos padrões já instituídos. Não à toa, Clara prefere o lugar onde está, já que é onde tem sua singularidade acolhida. Aliás, será que existe algum ser humano que prefira um lugar no qual as relações de trabalho sejam frias e com pouca perspectiva de criação a partir da singularidade que possui?

Outro oficinando da instituição mostra o quanto a dimensão afetiva é importante nos laços de trabalho. Maurício (MO.) trabalha numa empresa e comenta que das tarefas que realiza no seu setor, a que mais gosta de fazer é "bater papo com os amigos" (MO.). Quando perguntado se havia algum controle ou monitoramento, ele responde em tom inocente: "não, ninguém xingando, é só um bate papo" (risos) (MO.). A forma tranquila com que Maurício nos lembra da dimensão afetiva do trabalho coloca em questão o esquecimento dos espaços de interação na organização formal do trabalho.

Que espaço é reservado para os afetos nas organizações? E que significado têm as trocas afetivas para dar conta das regras e rotinas de trabalho? O que geralmente acontece é que "a máquina do trabalho busca engolir os corpos e anular suas diferenças, tentando transmutá-los assim em massas informes, sem rosto e sem nome" sendo apenas uma força de trabalho que recebe contornos estratégicos para a produção (Fonseca, \& Barros, 2010, p. 102). Nessa perspectiva, a deficiência coloca em questão a força de trabalho, pois seria improvável conseguir anular as singularidades que fogem da forma indicada como exemplo de boa dinâmica. Nessa incapacidade do sistema produtivo em transformar e uniformizar a deficiência, a estratégia é pintá-la com as cores da incapacidade, tornando desejável não a manutenção das singularidades, mas a produção do desejo de querer ser igual. Desejo produzido pelo que Foucault (2010) chama de Biopoder, 
uma estratégia de gestão que abrange todo o domínio do vivo e da existência humana a partir da disciplinarização dos corpos no regime disciplinar ou anotomopolítico, e a partir da regulamentação da vida e do indivíduo como espécie na biopolítica. Ou seja, desejo de linearização da vida que permite o mínimo de percalços e singularidades inusitadas, pavimentando as relações a partir da eleição de normas que baseiam o que é normal e o que é patológico (Canguilhem, 1990).

O que o campo possibilita pensar é que esse desejo, tão forte em alguns segmentos do mercado de trabalho, não se produz da mesma forma nessas inserções profissionais atravessadas pelos afetos. Aqui, o trabalho flui com o gostar, o conversar, o conhecer, o experimentar, o escolher, com o "jogar conversa fora". É importante salientar que pensar a questão do afeto nas relações de trabalho não é uma demanda apenas para as pessoas com SD. Não entendemos isso como uma característica específica da deficiência, mas talvez nos contextos de inserção padronizada no mercado de trabalho, os afetos fiquem rapidamente disciplinados pelos discursos da técnica, da eficiência e da objetividade, fazendo que as questões afetivas fiquem mais ofuscadas.

\section{Tempo e ritmo de trabalho}

Nos corredores já sinto o cheiro de tinta, entro na sala e procuro a professora Diana que está em meio aos alunos misturando tintas, inventando novas cores. E lá estão pintando garrafas, utensílios estes que já serviram para outras coisas, mas que agora viraram arte, a arte de cada um esculpida ali. Cumprimento a todos e percebo que há alguns alunos a mais naquela tarde. A professora Diana logo explica que alguns alunos da pré-oficina estão ali, pois a professora Ana estaria de atestado naquela semana. Hoje é o dia de entrevistar Rodrigo. Sento-me ao lado dele e ele continua seu trabalho, a professora diz para parar um pouco e prestar a atenção em mim, mas fico esperando ele terminar aquele vidro, e o artista segue seu trabalho. Do meu outro lado está Adriano, que seria aluno da pré-oficina, pintando um vidro também e que a cada pouco, busca minha atenção dizendo que os braços já estavam doendo. Interagi com ele e com o restante da turma enquanto Rodrigo terminava sua arte (Diário de campo, 18 agosto 2013).

Se pensarmos nas exigências do mercado de trabalho, ser um bom trabalhador é realizar um trabalho bem feito em um ritmo acelerado. Porém, essas exigências não são cabíveis quando tratamos de alguém com algum tipo de deficiência. Talvez, elas sejam incabíveis para quaisquer pessoas, mas a engenhosidade das formas contemporâneas de gestão faz com que sejam naturalizadas e inquestionáveis.

Na entrevista, Rodrigo conta empolgado sobre seus afazeres no interior, onde mora. Ajuda o pai na lavoura e a mãe dentro de casa: "Meu pai mata porco, mata galinha... tem gato lá, cachorro...". A professora conta que o pai se queixa às vezes que o filho é lento no trabalho, mas Rodrigo logo diz: "Meu pai é fraco!". Afinal, que ritmo de trabalho é esse que o pai tanto cobra? Quando perguntado se ele se considerava um bom trabalhador, afirmou sorridente que sim. É quando faz as coisas bem feitas (Diário de campo, 19 agosto 2013).

Ao analisar os materiais, percebemos formas de resistência ao trabalho serializado, algumas explícitas como na fala de Rodrigo, outras tímidas ou invisibilizadas. "Lutas que (re)sistem a uma lógica gestionária - arborescente e hierarquizante - que busca, embora lhe seja impossível conseguir, uma forma absoluta e totalizante de percorrer todo o processo" (Fonseca, \& Barros, 2010, p. 106).

Retomando o filme "O oitavo dia", podemos lembrar as falas de Harry, um alto executivo de um banco que tem como uma de suas tarefas no trabalho ensinar os funcionários o caminho para o sucesso: 
Isso interessa a todos, porque todos vendem. Nós todos nos vendemos algum dia. Mantenha quatro regras básicas: 1. Olhe o consumidor nos olhos; 2. Sorria; 3. Dê a impressão de sucesso. As pessoas preferem uma pessoa bem-sucedida a um perdedor; e 4. Seja entusiasmado. Entusiasmo é contagiante (Godeau, 1996).

A cena segue sem fala, mostrando a vida privada do personagem, inundado num momento melancólico ao chegar em casa e vê-la vazia após o divórcio e o afastamento das filhas. Ao acordar na manhã seguinte, se arruma e segue para o trabalho, e no caminho antecipa o discurso de mais uma palestra motivacional que fará em seguida, mostrando seu cotidiano contraditório e o vazio do discurso que não encontra formas de dar significado ao que fala: "Tenha uma convicção inabalável e você vencerá. Pense positivo, só use palavras positivas. Elimine as palavras negativas. Seja orgulhoso, mas não vá sorrir para o espelho toda a manhã. Sejam orgulhosos de si mesmos, de si mesmos e do banco". Essas são algumas formas de sedução e padronização do trabalho na contemporaneidade: fórmulas mágicas e fugazes que nos mostram como agir, intensificando o ritmo de trabalho implantado em uma busca constante de mais rapidez e sucesso.

Segundo Silva e Palhano (2001), é preciso compreender que a pessoa com deficiência possui capacidades e também especificidades que não devem ser ignoradas. Suas limitações e possibilidades lhes são próprias, assim como são próprias as limitações e possibilidades de cada sujeito quanto ao aspecto social, pois a presença de limites é uma constante na vida de todos os seres humanos. Essa questão aparece como preocupação na fala das professoras Diana (D.) e Marcela (MA.):

Aqui a gente consegue organizar de uma maneira que envolva eles, que eles gostem e se sintam bem. Mas num trabalho de empresa lá fora daí já é um pouco mais difícil (D.).

São muito caprichosos, alguns podem até ser mais lentos, mas eles são caprichosos (...) então, aqui é um trabalho no qual eles podem ficar sentados, sem serem muito pressionados (MA.).

Talvez essa preocupação possa estar atrelada ao fato de não haver um espaço no trabalho formal para ser diferente, onde o ritmo de cada um seja respeitado, e isso evidencia o quanto as formas de produzir estão hoje atreladas a modos de ser na sociedade. As professoras trabalham com tentativas e erros ao designar atividades as quais, muitas vezes, não são bem aceitas e muito menos realizadas. Assim, "eles participam ativamente do processo de trabalho, instituindo escolhas e modos de fazer que se diferenciam das normas prescritas" (Fonseca, \& Barros, 2010, p. 110).

Chego a uma das salas e percebo que duas turmas foram agrupadas: os alunos da Pré-Oficina e os da Oficina Terapêutica Produtiva II. É dia de empacotamento de papel higiênico. Esse trabalho é terceirizado para uma empresa da região. Logo me dou conta de que as turmas foram agrupadas para um maior rendimento no empacotamento (ou seria para um maior entretenimento?). Eu diria que para os dois. Entro na sala e já nem quero mais sair. Risos contagiantes, olhares curiosos, assuntos intermináveis, pensamentos flutuantes. Todos estão ao redor de uma mesa produzindo, rindo e conversando, cada um com suas peculiaridades. Quando me veem, me cumprimentam alegres, uns mais timidamente, outros com abraço, outros nem levantam a cabeça, afinal, é preciso prestar atenção no trabalho que está sendo feito. Sinto a falta de alguns integrantes do grupo e as professoras já dizem: "Devem estar chegando!". Não tem nenhum ponto para bater ali, eles vão chegando a hora que quiserem e chegam por que querem e sentem-se à vontade (Diário de campo, 28 agosto 2013).

Embora a instituição possua normas e horários de funcionamento, tudo é construído e flexibilizado a partir do funcionamento de cada um. O importante é estar ali, criar vínculos e sentir-se parte daquele 
ambiente no qual "o fazer diferente assume importância capital, [...] escolhas que os seres humanos têm de fazer para fazer valer suas próprias normas de vida" (Fonseca, \& Barros, 2010, p. 108).

\section{Família e remuneração}

Uma questão que foi sendo marcada como algo relevante na forma como percebem o trabalho é a questão da remuneração, além da articulação com a família, que em algumas situações, se responsabiliza e responde pela pessoa com SD. Quanto à renda, as Oficinas Terapêuticas Produtivas I e II são preparatórias para o mercado de trabalho, e o que é produzido nelas gera uma renda que era dividida, até 2012, entre a escola (para reposição de materiais) e os alunos. Cada aluno podia fazer o que bem entendesse com o dinheiro. Porém, as professoras notaram que aquele retorno financeiro não era tido como algo prazeroso. Em reunião com os alunos e com os seus responsáveis, todos decidiram utilizar o dinheiro para atividades que envolvessem o grupo, inclusive os alunos da Pré-Oficina, como passeios, viagens para conhecimento, entre outras. Fato verificado nos depoimentos de Camila (CM.), Clara (CR.), Adriano (AD.) e Rodrigo (R.) - alunos - e Marcela (MA.) - professora:

Quando a gente reverteu isso pra esses passeios, todos foram igualados, e foi uma coisa bem diferente juntar todo esse dinheiro e proporcionar pra todos eles né... afinal, isso tudo foi gerado com o trabalho deles (MA.).

Dormi numa cama bem quentinha lá! E também vimos boi, vaca, cavalo e andamos de carroça... (CM.).

Foi muito bonita a viagem... Andamos de carroça de boi, de cavalo, de bicicleta... e comemos em uma pizzaria! (CR.).

Com o dinheiro a gente foi viajar... num hotel... hotel fazenda. Foi bem legal! (AD.).

Eu adoro tirar fotos nas viagens, tenho uma câmera. (R.).

Como corresponsáveis pelos jovens, as famílias são envolvidas nas decisões relativas à renda. Essa previsão legal busca proteger a pessoa com SD, mas na mesma ação, ratifica a concepção de que teriam pouca capacidade para realizar suas escolhas, necessitando do auxílio dos "sãos" na administração de suas finanças. Obviamente, a possibilidade de realizar uma decisão coletiva sobre o que fazer com o dinheiro parece interessante, pois há uma interação na qual todos se comprometem a pensar no que farão com os recursos de seu trabalho. Contudo, podemos questionar até que ponto essa prática cristaliza a força tuteladora que perdura por séculos no que tange ao trato dos considerados desarrazoados (Foucault, 2008). Essa tutela que deslegitima o direito de escolha, nesse caso em função da SD, ainda é um desafio a ser politicamente problematizado nas relações de cuidado, aprendizagem e trabalho com aqueles que possuem algum tipo de deficiência, posto que esse modo de viver tutelado seja deveras mortificador do desejo e da singularidade.

As contradições entre escolha e tutela acompanham as negociações familiares e institucionais. No caso de Adriano, o médico que o entrevistou para a perícia do INSS $^{10}$ alega que ele tem capacidade de trabalhar e que não necessita continuar recebendo o benefício. Adriano também acha isso, mas sua mãe, não.

10 Instituto Nacional do Seguro Social. Órgão do Ministério da Previdência Social responsável pelo pagamento de aposentadorias e demais benefícios para aqueles que adquirem os direitos a estes benefícios, segundo o previsto em lei.

\section{8}


Como parte da Política Nacional da Pessoa com Deficiência, o Benefício de Prestação Continuada (BPC), assegurado pelos artigos 21 e 22 da Lei Orgânica da Assistência Social - Lei no 8.742, de 7 de dezembro de 1993 - é uma transferência incondicional de um salário mínimo mensal para idosos ou pessoas com deficiência ${ }^{11}$. Entretanto, a concessão do benefício está sujeita "a exame médico pericial e laudos realizados pelos serviços de perícia médica do INSS" (Brasil, 1993b).

Capacidade ou incapacidade? Deficiência, eficiência ou ineficiência? Essas palavras são contrárias? Ou uma ou outra? A forma como está estabelecida a lei e como é compreendida pelas famílias pode produzir alguns significados distintos para vários desses conceitos. Pode, inclusive, parecer que há um desejo da família de que o familiar seja categorizado como incapaz, assegurando ao menos algum recurso provindo da pessoa com deficiência. Inclusive, se a família entende que essa é a forma de acesso ao benefício, buscará formas de enquadrá-lo nessa classificação/ estigmatização que tanto restringe as possibilidades existenciais.

Podemos compreender que receber o benefício explicita a necessidade de uma proteção do Estado por conta de sua diferença, mas a concessão do benefício pode representar uma exclusão maior em relação ao mercado de trabalho, incorporando o rótulo da incapacidade para o trabalho como um conceito total que o incapacita permanentemente para qualquer atividade ${ }^{12}$. Rodrigo, o filho do agricultor, não recebe nenhum benefício, dependendo, portanto, da renda familiar - que também é produzida por ele, tendo em vista a sua participação nas tarefas - para viver, apesar de o pai achar que o filho poderia render mais na lavoura. Acompanhando o pai na produção, Rodrigo cria outras estratégias, as quais lhe permitem um retorno financeiro deste trabalho, como, por exemplo, quando vende ovos. Com esse dinheiro ele comprou sua câmera digital - um sonho realizado. Agora quando viaja com os colegas, leva consigo a câmera para registrar todos os momentos.

\section{Considerações finais}

De uma maneira geral, resgatando nosso objetivo inicial - compreender os enunciados construídos por pessoas com SD a respeito do trabalho e da inclusão em atividades produtivas - podemos sintetizar que os enunciados são diversos e apontam para a complexidade do campo. Os enunciados analisados e que atendem esse objetivo nos apontam para a importância de três temáticas na forma como as pessoas com SD se relacionam com o trabalho e a inclusão: 1. Há uma grande importância na construção de vínculos nas relações de trabalho, que podem até influenciar as escolhas de atividades e locais; 2 . O ritmo de trabalho é construído de forma diferenciada e coloca em questão as clássicas pressões de produtividade nas empresas; e 3. As questões de remuneração e família tensionam as possibilidades de escolha e tutela das pessoas com SD.

Entretanto, entendemos que este estudo, mais do que sintetizar e fixar os enunciados a respeito do trabalho e da inclusão, podem lançar novos significados para trabalhadores com ou sem SD. Pode significar o prazer de bater papo com os colegas, de comer o lanche oferecido, de poder comprar uma roupa, uma câmera digital e ajudar a família. Trabalho esse que respeite o ritmo de cada um, seja pintando uma garrafa, empacotando papel higiênico, ajudando nos afazeres domésticos ou recolhendo ovos. O significado aqui não está atrelado ao retorno financeiro ou mesmo ao status de competência profissional, mas ao reconhecimento enquanto sujeito. Será que

11 O parágrafo 2ํำ do artigo 20 explana que, para a concessão desse benefício, "a pessoa portadora de deficiência é aquela incapacitada para a vida independente e para o trabalho".

12 Há na lei a previsão da suspensão do benefício em caso de atividade remunerada, mas também a possibilidade de requerer a continuidade do pagamento quando a atividade acabar (Lei no 8742/93). 
colocar em questão o trabalho para esses trabalhadores - pessoas com Síndrome de Down - não seria também colocar em questão o trabalho na contemporaneidade? A possibilidade de partirmos da fala desses sujeitos para pensarmos o trabalho enquanto construção social é também questionar as categorias que definem o que é ser diferente, normal, deficiente, trabalhador e incluído.

Não desejamos chegar a uma conclusão, a uma verdade, mas podemos elencar algumas questões para que possamos refletir. Escutando o que cada entrevistado trouxera nestes encontros, podemos pensar a própria Lei de Cotas. Se de um lado essa Lei possibilita que as PCDs tenham o direito ao trabalho como qualquer outro cidadão, por outro, acaba os engessando em atividades prescritas que não condizem com seus desejos. Será que para ser legitimado como sujeito é preciso estar trabalhando formalmente, "contribuindo com sua parte para nosso belo quadro social13"? Será que as instituições que trabalham com os deficientes, e mesmo as famílias, estão preparadas para escutar o desejo dele, sem achar que são vagarosos e pouco habilidosos para lidar com dinheiro? Será que as empresas, ávidas pelo preenchimento das cotas, estão preocupadas em repensar sua lógica de trabalho para uma melhor acolhida das diferenças? Temos fôlego para aguentar a relação com a diferença ou desejamos apenas ficar nesse lugar do politicamente correto que pouco transforma as relações sociais para além de um discurso maquiadamente bonito? Eis as questões pertinentes que não demos conta de responder, apesar do esforço que realizamos para pensá-las, mas que desejamos expor, no intuito de que possam servir como reflexão a todos que tenham interesse por este estudo aqui apresentado.

\section{Referências}

Birman, J. (2003). Malestar na atualidade: a psicanálise e as novas formas de subjetivação (4a ed.). Rio de Janeiro: Civilização Brasileira.

Brasil (1981). Comissão Nacional. Relatório de atividades. Ano internacional das pessoas deficientes. Brasília. Recuperado de https://goo.gl/yDC9QS [17 abril 2016]

Brasil (1991). Lei no 8.213, de 24 de julho de 1991. Dispõe sobre os Planos de Benefícios da Previdência Social e dá outras providências. Diário Oficial da União, Seção 1, Brasília. Recuperado de http://www.planalto.gov.br/ccivil_03/leis/ L8213 compilado.htm [06 maio 2013]

Brasil (1993a). Decreto no 914, de 06 de setembro de 1993. Institui a Política Nacional para a Integração da Pessoa Portadora de Deficiência. Diário Oficial da União, Seção 1, Brasília. Recuperado de https://goo.gl/H3OgKv [06 maio 2013]

Brasil (1993b). Lei no 8.742, de 07 de dezembro de 1993. Dispõe sobre a organização da Assistência Social e dá outras providências. Diário Oficial da União, Seção 1, Brasília. Recuperado de http://www.planalto.gov.br/ccivil_03/leis/ 18742.htm [21 outubro 2013]

Brasil (1999). Decreto no 3.298, de 20 de dezembro de 1999. Regulamenta a Lei no 7.853, de 24 de outubro de 1989, dispõe sobre a Política Nacional para a Integração da Pessoa Portadora de Deficiência, consolida as normas de proteção, e dá outras providências. Recuperado de http://www.planalto.gov.br/ccivil_03/decreto/d3298.htm [12 janeiro 2017]

Canguilhem, G. (1990). O normal e o patológico. Rio de Janeiro: Forense Universitária.

Cunningham, C. (2008). Sindrome de Down: uma introdução para pais e cuidadores (3a ed.). Porto Alegre: Artmed.

Deleuze, G. (1992). Conversações (trad. Peter Pál Pelbart). São Paulo: Editora 34.

Fávero, E. A. G. (2007). O direito a uma educação inclusiva. In M. A. Gugel, W. M. Costa Filho, \& L. L. G. Ribeiro (Orgs.), Deficiência no Brasil: uma abordagem integral dos direitos das pessoas com deficiência (pp. 89-109). Florianópolis: Obra Jurídica.

13 Trecho da música "Ouro de Tolo", de Raul Seixas. 
Fonseca, T. M. G., \& Barros, M. E. B. (2010). Entre prescrições e singularizações: o trabalho em vias da criação. Fractal: Revista de Psicologia, 22 (1), 101-114.

Foucault, M. (1984). Microfísica do poder (4a ed.). Rio de Janeiro: Edições Graal.

Foucault, M. (2005). A arqueologia do saber (7a ed). Rio de Janeiro: Forense Universitária.

Foucault, M. (2008). História da loucura: na idade clássica (trad. José Teixeira Coelho Netto). São Paulo: Perspectiva.

Foucault, M. (2010). Em defesa da sociedade: curso no Collège de France (1975-1976) (trad. Maria Ermantina Galvão). São Paulo: Martins Fontes.

Freitas, M. N. C., \& Marques, A. L. (2009). Trabalho e pessoas com deficiência: pesquisas, práticas e instrumentos de diagnóstico. Curitiba: Juruá.

Liedke, E. R. (1997). Trabalho. In A. D. Cattani (Org.). Trabalho e tecnologia: dicionário crítico (pp. 268-274). Petrópolis: Vozes.

Manzini, E. J. (1990). A entrevista na pesquisa social. Didática, São Paulo, 27, 149-158.

Nardi, H. C. (2006). Ética, trabalho e subjetividade: trajetórias de vida no contexto das transformações do capitalismo contemporâneo. Porto Alegre: UFRGS.

Oliveira, A. A. S., \& Leite, L. P. (2002). O papel da educação especial no sistema educacional inclusivo. Diário de Marília, Marilia, 24 outubro.

Pelbart, P. P. (2003). Vida capital: ensaios de biopolítica. São Paulo: Iluminuras.

Sassaki, R. K. (1997). Inclusão: construindo uma sociedade para todos. Rio de Janeiro: WVA.

Silva, A. G., \& Palhano, E. G. da S. (2001). Formação profissional: uma alternativa inclusiva para pessoas com deficiência. Associação Nacional de Pós-Graduação e Pesquisa em Educação. Recuperado de http://28reuniao.anped.org.br/ textos/gt15/gt151566int.rtf [12 janeiro 2017]

Toni, M. (2003). Visões sobre o trabalho em transformação. Sociologias, Porto Alegre, 5 (9), 246-286.

Violante, R. R., \& Leite, L. P. (2011). A empregabilidade das pessoas com deficiência: uma análise da inclusão social no mercado de trabalho do município de Bauru, SP. Cadernos de Psicologia Social do Trabalho, 14 (1), 73-91.

Wuo, A. S. (2007). A construção social da Síndrome de Down. Cadernos da Psicopedagogia, 6 (11), 1-18.

Zanelli, J. C., Andrade, J. E. B., \& Bastos, A. V. B. (2004). Psicologia, organizações e trabalho no Brasil. Porto Alegre: Artmed.

\section{Endereço para correspondência}

dalilagiacomini@hotmail.com, lisandra.moreira@ip.ufal.br,

Recebido em: 08/05/2015 francislonder@hotmail.com

Revisado em: 26/04/2016

Aprovado em: 07/12/2016 